\title{
Public Health and Health Education in Faith Communities
}

\author{
Linda M. Chatters, $\mathrm{PhD}$ \\ Jeffrey S. Levin, PhD, MPH \\ Christopher G. Ellison, PhD
}

\begin{abstract}
This special issue of Health Education \& Behavior is devoted to broadly examining the interconnections among public health, health education, and faith-based communities. In addition to a focus on questions related to the practice of public health and health education within religious settings (e.g., program development, implementation, and evaluation), the articles in this issue examine a broad range of both substantive and methodological questions and concerns. These articles include contributions that address (1) various theoretical and conceptual issues and frameworks explaining the relationships between religious involvement and health; (2) substantive reviews of current research in the area; (3) individual empirical studies exploring the associations between religious involvement and health attitudes, beliefs, and behaviors; (4) evaluations of health education programs in faith communities; and (5) religious institutions and their contributions to the development of health policy. The articles comprising the issue are selective in their coverage of the field and provide different and complementary perspectives on the connections between religious involvement and health. It is hoped that this approach will appeal to a broad audience of researchers, practitioners, policy makers, and others from health education, public health, and related social and behavioral science disciplines.
\end{abstract}

\section{RELIGION AND HEALTH: BACKGROUND}

Empirical research on religious factors in health and illness dates to the past century. ${ }^{1}$ This early work, exemplified by Durkheim's classic La Suicide in 1897 (as cited in Levin and Vanderpool ${ }^{1}$ ), was characteristic of efforts to delineate what became known as the epidemiologic triangle, or agent-host-environment model of population-level disease causation. Religious identity - just like race, ethnicity, nationality, and social class-was discovered to be a potential source of variation in morbidity and mortality, and both public health and medical researchers began in earnest to examine such rates in relation to religious variables. No less a figure than Sir William Osler, considered by many to be the father of modern Western biomedicine, described the salutary benefits of faith in the Brit-

Linda M. Chatters is an associate professor in the Department of Health Behavior and Health Education at the University of Michigan, School of Public Health. Jeffrey S. Levin is a social epidemiologist and senior research fellow with the National Institute for Healthcare Research, Rockville, Maryland. Christopher G. Ellison is an associate professor in the Department of Sociology, University of Texas.

Address reprint requests to Linda M. Chatters, University of Michigan, School of Public Health, 1420 Washington Heights, Ann Arbor, MI 48109-2029; phone: (734) 647-3178; fax: (734) 763-7379; e-mail: chatters@umich.edu

Our thanks to members of the editorial board of this special issue, who helped to make this volume possible; to Barbara Israel for her support and encouragement; and to Marge Ryan, who contributed to every stage of the editorial process. 
ish Medical Journal in $1910,{ }^{2}$ and a series of di . _usuus of religious healing even appeared in $J A M A^{3}$ in 1926. This prominence of religion in health-related discourse, however, soon faded.

As the practice of medicine changed-becoming more rationalized, committed to high-technology diagnostic and therapeutic procedures, and buoyed by the promise of one-shot cures such as antibiotics - context-rich perspectives on determinants of health (i.e., the epidemiological triangle) were pushed to the background. Epidemiological studies of religion continued but were not part of any program of research, and little attention was paid to significant findings, despite their accumulation in great numbers. Beginning in the 1950s, several factors saw the pendulum start to swing back in favor of a wider consideration of environmental, social, psychological, and behavioral determinants of health, including religious identity and practice.

First, religion was a key component of models of health and well-being devised by researchers in the new field of social gerontology. Moberg, ${ }^{4}$ for one, was instrumental in producing findings pointing to a protective effect of religious involvement in the lives of older adults. Second, early work in psychiatric epidemiology revealed the psychosocial etiology of mental illness, including variation in rates of morbidity by categories of religious identity and practice. The Midtown Manhattan Study, ${ }^{5}$ for example, documented considerable prevalence differences in mental illness by degree of religious involvement. Third, the rebirth of social epidemiology led to greater consideration of supportive networks and interpersonal relationships as sources of epidemiological protection. The work of Cassel and associates at the University of North Carolina at Chapel $\mathrm{Hill}^{6}$ encouraged inclusion of religious variables in numerous epidemiologic studies throughout the 1970s, such as the Evans County Study. ${ }^{7}$ Together, these factors influenced the reengagement of religion by public health and clinical researchers. Furthermore, these developments stimulated the interests of Koenig, Levin, Larson, Idler, and others who began in the mid-1980s to review this prior work and to investigate religious factors in health more directly.

More recently, the revival of interest in religious factors in health is especially indicated by several factors. First, many recent books and literature reviews have focused attention on the large body of empirical research findings that have accumulated over the past several decades. These include findings linking religious involvement with a diverse array of physical and mental health outcomes..$^{8-11}$ Broadly, these studies include investigations of various indicators of physical and mental health status, ${ }^{12-16}$ morbidity and mortality rates, ${ }^{17,18}$ quality-of-life indicators, ${ }^{19-22}$ discrete health behaviors and attitudes, ${ }^{23}$ and use of health care resources. ${ }^{24}$

This research literature spans a century and involves diverse groups of individuals with respect to ethnicity, religious affiliation, age cohort, and social class ${ }^{25}$ (in this volume, Ellison and Levin provide a succinct review of this literature). Notwithstanding important methodological reservations concerning some of these investigations, ${ }^{10}$ the evidence suggests, on balance, the presence of a salutary effect of religious factors on mental and physical health and health-related attitudes and behaviors. ${ }^{25}$

A second indicator of the renewed interest in this area is the recent theoretical and conceptual developments that focus attention on the specific manner by which the health of individuals and populations is linked to religious and spiritual concerns. These developments include the elaboration of models that (1) specify the relationships between religious involvement and measures of physical and mental health and well-being and (2) describe the psychosocial mechanisms that may account for the effects of religious involvement on health outcomes. These efforts frame various aspects of religious 
involvement within extant models of social and health-related behaviors (e.g., stress and coping, social support, life stress paradigm), thus providing appropriate theoretical grounding. ${ }^{8,10-12}$ Corollary efforts have focused attention on a number of methodological issues and concerns inherent in this work, such as the measurement of various domains of religious involvement. ${ }^{26-28}$

A third indicator of the growing popularity of these topics is the fact that public health and health education have an established tradition of practice within faithbased communities that encompasses, among other concerns, health screenings, health promotion and disease prevention, and risk reduction. Representative programs and activities include church-based health centers, ${ }^{29}$ church-based health promotion/disease prevention interventions involving diabetes, hypertension, and maternal and child health; ${ }^{30,31}$ community mental health counseling and training programs; $;^{32-34}$ and health policy initiatives. Partnerships between public health and faith-based communities are perhaps most readily identified within the African American population (i.e., public health interventions and programs that are based in African American churches or that serve a portion of church communities), and a tradition of practice reflects this longstanding collaboration. ${ }^{35,36}$ However, health programs within a wide array of faith-based settings are gaining broad-based support from representatives of religious institutions and public health professionals. ${ }^{37-41}$

Finally, the current national zeitgeist reflects an intense focus on religious and spiritual matters. This interest is evident not only in academic literature but also in popular culture, with these topics occupying a prominent place in national news magazines (e.g., Time, Newsweek, The New York Times Magazine), as well as best-selling books. Despite widespread assumptions within academia and among the literate public that modernization has produced secularization throughout the 20 th century, a number of developments over the past three decades have called such assumptions into question. ${ }^{42}$ For instance, between $25 \%$ and $40 \%$ of Americans attend some type of religious services within a given week, and large majorities of Americans engage in private acts of devotion (e.g., prayer, meditation) and believe in God and in an afterlife. ${ }^{43}$ For the most part, such survey figures have not declined substantially in recent decades (although methodological issues in church attendance rates are of note) ${ }^{44} \mathrm{New}$ religious groups (e.g., cults, sects, schismatic movements) continue to emerge and attract devoted followers. Religious actors, symbols, and values have played pivotal roles in various contemporary social and political movements in the United States (e.g., the Christian Right) and elsewhere. In recent years, growing recognition of these and other developments has fueled a new wave of social and behavioral science research, exploring the links between religious involvement and family life, civic commitment, political attitudes and behavior, and other domains of life experience. $^{45}$

Within this environment, interest in the impact of religious factors on mental and physical health (including mortality risk) has mushroomed. While this area of inquiry is not new, as we noted earlier, contemporary research embodies greater theoretical sophistication, conceptual clarity, and methodological rigor than the earlier generation of studies. Despite these considerable advances, however, much work remains if we are to gain a sound understanding of the multifaceted influences of religion and spirituality on health. Further attention to these complex questions promises to advance the scholarly literature and is aimed at benefiting the public's health in direct and tangible ways. 


\section{CHALLENGES, ADVANTAGES, AND OPPORTUNITIES}

As both empirical and theoretical literature in the area of religion and health has flourished, so have the challenges, advantages, and opportunities for research and practice in the field of health education and behavior. The purpose in describing the challenges here is not to arrive at definite statements regarding their status or strategies for resolving apparent differences but to suggest that these are long-standing concerns that deserve our ongoing attention. Our discussion focuses on two general issues: the conflicts between religious and public health worldviews and the nature of ethical issues for public health practice in faith-based settings. Following this is a discussion of the advantages of developing religion-public health partnerships and the opportunities for practice and research that are provided by these partnerships.

\section{Challenges to Religion-Public Health Partnerships}

Difficulties and apparent conflicts between religious and public health worldviews are fairly long-standing and likely a variant of the often antagonist relationship between the domains of religion and science. Both parties demonstrate an aversion to the other's underlying perspectives and assumptions, contributing to a sense of mistrust and lack of understanding. Within public health circles, the domain of religion is often seen as an adversary, despite considerable evidence suggesting a role for religious belief and practice in shaping physical and mental health. This perspective has worked against efforts to promote alliances with religious institutions and to draw on personal religious resources to promote health and prevent illness. This is clearly unfortunate, as there have been considerable programmatic successes in designing public health interventions that capitalize on the prominent place of religion in communities and in the lives of individuals. ${ }^{46-48}$ At a more basic level, health professionals must confront their own assumptions concerning the appropriate roles of science and faith as they relate to health, as well as their preconceptions for or against particular religious beliefs and lifestyles. ${ }^{25}$

Efforts to conduct research and practice in the area of religion and health are often met with skepticism on the part of religious institutions and their representatives regarding the motivations of public health professionals and/or outright rejection of the idea that religious matters are appropriate topics for scientific inquiry. Anyone who has attempted to conduct church-based health interventions is aware of the difficulties often encountered in initiating such efforts and the pivotal role that clergy play in their acceptance and implementation. In many respects, these conflicts reflect basic issues of territory encroachment, disputes concerning the appropriate roles of clergy versus health professionals, authority to define particular behaviors as illness or as moral limitations, and, given a particular definition, what are the appropriate measures to be pursued to ameliorate the condition. Furthermore, for religious institutions in minority communities (e.g., Black churches), resistance to public health interventions may reflect long-standing mistrust of formal institutions, prior patterns of underutilization of health services as well as being underserved, and discrimination and prejudice on the part of the health and medical professions in dealing with minority communities. ${ }^{36}$

Although questions of ethics are inherent to all public health and health education efforts, they may be particularly conspicuous and significant when the form, substance, and arena of professional practice involve religious content or a faith-based setting. Health professionals are governed by a code of ethics that recognizes that the notions of 
individual autonomy and self-determination, as well as informed consent, are operative in matters of health and the provision of health care services. ${ }^{49}$ To varying degrees, these ethical principles are familiar to and prescriptive of the behaviors of individuals and organizations who represent religious institutions and interests. However, despite a shared concern with the health of communities and a recognition of ethical guidelines, differences and disagreements will occur in the context of public health interventions, whether they are focused on an individual or on a group within a faith-based setting.

For example, disagreements over the appropriate content of sexuality and sexually transmitted disease (STD) education programs (e.g., abstinence-only vs. full-option programs), in which the health professional and the faith-based community clearly espouse different values and goals, are possible. Given these conflicts, how and in what manner should the health professional respond? How might these differences be resolved? In situations where individual and group interests are in conflict, whose rights and interests should be protected? Professionals face questions as to whether religious content of any form is an appropriate component of public health and health education research and interventions. Accordingly, this brings up issues related to the sources of funding (e.g., federal and state health care programs) for treatment and research that involve religious factors and the nature of the institutional contexts (e.g., government vs. privately funded hospitals, clinics) within which these activities occur.

\section{ADVANTAGES OF RELIGION-PUBLIC HEALTH PARTNERSHIPS}

The placement of community-wide health programs within churches has advantages, particularly given a similar ethic of service to others that undergirds both religious institutions (e.g., the Black church) and public health. ${ }^{35,50}$ Several authors commenting on this tradition note that religious institutions and public health embody a set of common values, core principles, and roles they perform with respect to health issues and the delivery of care ${ }^{35,36}$ Pastors are particularly noted for their efforts in the areas of primary, secondary, and tertiary prevention, ${ }^{32-34,51-53}$ as well as in serving as catalysts for health-related behavioral and social change. ${ }^{36}$

Furthermore, religious institutions (the Black church, in particular) often occupy pivotal roles in their communities with respect to economic, educational, civic, political, and social welfare concerns. As a consequence, they possess community legitimacy, as well as the organizational structures and roles that facilitate the incorporation of relevant health programs within their settings. The existence of this prior work functions as a solid foundation on which to develop new collaborative arrangements with an important community resource and institution, as well as to expand the existing roles of churches and clergy with respect to community health.

The advantages of locating health interventions in faith-based settings in terms of community access and legitimacy are generally acknowledged within health education practice. However, faith-based health interventions often fail to fully account for the particular features, characteristics, and dynamics operating within the institutional (e.g., church, synagogue) and broader community settings. As a result, the intervention literature often reflects a "one-size-fits-all" approach in which issues of organizational characteristics, capacities, and resources are given short shrift in the development and implementation of programs. In contrast, one study of African American churches in the Northeast region ${ }^{54}$ identified several congregational characteristics (e.g., clergy leader- 
ship attributes, congregational age, and socioeconomic status) that were associated with the development and successful implementation of church-based outreach programs. Furthermore, both the epidemiologic and intervention literatures often reveal an overreliance on relatively simple measures of religious involvement (e.g., rates of religious service attendance, faith affiliation) that likely serve as proxies for other classes of religious behaviors and attitudes. This practice reflects a tacit assumption that religious indicators are largely interchangeable, indicating a need for greater attention both to conceptualization and measurement issues and the specific mechanisms through which religious involvement is linked to health.

Systematic research on the relationships between religion and health will serve to advance health education practice and research. This information will provide a more complex and differentiated depiction of the role of religion in shaping the health status and behaviors of individuals, as well as the development of health education programs within faith-based settings. For example, research addressing the various dimensions of religious involvement (e.g., organizational, nonorganizational, and subjective religiosity) is helping to provide conceptual and measurement clarity that will enhance our understanding of potential explanatory mechanisms. . $^{26,2755,56}$ Several conceptual models broadly classify explanations for religious effects on health as falling within the domains of (1) health behaviors and lifestyle, (2) religious coping strategies and resources, (3) enhancement of social resources (i.e., social support and integration), (4) enhancement of personal resources (positive self-perceptions such as self-esteem, personal efficacy, and self-worth), and (5) imparting positive emotions and beliefs (see Ellison and Levin in this issue). A thorough understanding of these types of potential explanations will assist in the development, implementation, and evaluation of planned intervention strategies that embody religious content.

Finally, as more information accrues concerning the specific mechanisms linking religion and health, the significance of status group and other factors (e.g., age, race/ethnicity, gender, socioeconomic status, region, denominational affiliation) that are consequential for religious involvement (and that potentially modify these relationships) will be elaborated. Attention to these issues will help to delineate whether specific types and strategies of faith-based health interventions are differentially appealing and effective for subgroups of the population. As the literature linking religion and health matures, health educators will be in a better position to design specific and targeted interventions that clearly reflect the proposed mechanisms by which religion affects health-as well as the relevant features of the institutional and community contexts within which they take place - that may serve to facilitate or hinder their development. As a result, we will have the ability to more closely observe and assess how and under what circumstances faithbased interventions have or have not been effective and for which types of problems.

\section{Opportunities for Religion-Public Health Partnerships and Practice Implications}

As indicated above, prior reviews of the literature ${ }^{57}$ have outlined areas of commonality between public health and faith-based settings and how cooperating with religious institutions and mobilizing religious resources may contribute to public health objectives. For health educators, religious practices and institutions may be significant allies in needs assessment and in the planning and implementation of interventions in at least three general ways. 
First, religious content can be included in community needs assessments. In light of epidemiologic evidence that religious affiliation and participation influence population-wide rates of risk and protection, personal religious information (e.g., attendance patterns, beliefs, attitudes, behaviors) and community religious demographics (e.g., denominational breakdowns, numbers of churches and synagogues, numbers of clergy) may provide basic data that can inform the planning of social and behavioral change interventions. Personal religious histories and operant belief systems of particular congregations may offer clues about the feasibility of specific intervention strategies in certain settings. Securing the support and involvement of religious community leaders in the needs assessment phase of a program can be helpful in identifying religious sources of both cooperation and barriers to change.

Second, information about the religious lives of individual community members may be valuable for planning interventions based on various social and behavioral change theories. Aspects of religious and spiritual belief and practice may directly reinforce, enable, or predispose health-related behaviors, the functioning of socially supportive networks, and the manifestation of various psychosocial states, traits, and resources. Certain religious belief systems oriented around heightened personal piety may be amenable to health-related messages encouraging changes in behavior. Other theologies or particular congregations with strong traditions of viewing collective action and social justice concerns as manifestations of holiness may be open to working together for macrolevel, policy-oriented changes (e.g., through local governments).

Finally, religious congregations themselves may serve as the headquarters for health promotion and disease prevention activities, in the tradition of church- and synagoguebased health education programs, especially within African American churches of the South. ${ }^{30,31}$ Church-based health education efforts have met with considerable success in identifying members of at-risk populations, making referrals to health care providers, and reaching communities with interventions that have prevented or reduced subsequent morbidity. The success of these programs, more than anything else, serves to demonstrate the "bottom-line" relevance of religion for public health practice.

\section{OVERVIEW OF THE SPECIAL ISSUE}

The collection of articles in this special issue reflects a variety of topic areas pertaining to the relationship between religion and health. As a group, they cover a spectrum of issues ranging from theoretical and conceptual models describing the relationship between religion and health to specialized health intervention programs within faithbased communities. The article by Christopher G. Ellison and Jeffrey S. Levin provides a comprehensive review of the literature linking religion and health. The authors summarize major empirical findings from this burgeoning literature and outline the major theoretical models and causal mechanisms underlying the religion-health connection. In addition, they identify a number of important directions for future research, including the need to distinguish carefully between positive and negative effects of religious belief and practice and the need to explore subgroup (e.g., race/ethnicity, gender) variations in religious effects on health outcomes. John M. Wallace Jr. and Tyrone A. Forman address the relatively neglected topic of the relationship between religion and the health of adolescents, with particular attention to both positive (e.g., proper nutrition) and negative (e.g., substance use) lifestyle behaviors. The focus on religion's role as a protec- 
tive factor for the health of adolescents is particularly timely and addresses a major gap in a literature that is largely focused on adults. Sarah A. Fox and her colleagues report on a church-based health education and promotion program for breast cancer screening adherence (i.e., mammography and clinical breast examination). Their findings suggest that church membership may be influential for breast cancer screening, independent of income and educational levels.

Two articles address (1) the church as a context for institutional resources and personnel that are useful in addressing personal problems and (2) the relationships between churches as a context for informal help seeking and the professional health community. Harold W. Neighbors, Marc A. Musick, and David R. Williams examine the role that ministers play in relation to the help-seeking behaviors of African Americans for serious personal problems. Their particular interest lies in understanding what factors are associated with turning to clergy for help, patterns of professional and clergy help seeking, and the types of assistance offered by clergy. Mary B. McRae, Patricia M. Carey, and Roxanna Anderson-Scott focus on the characteristics of the Black church that constitute a therapeutic system. In particular, they examine the resources and processes operating within Black churches in relation to both systems theory and group relations theory. This work draws attention to important similarities in how Black churches operate in addressing the expressed needs of their members, as well as the characteristics that distinguish them from one another as they fulfill this mission. The final article by Antonia van Loon describes the faith community nursing ( $\mathrm{FCN}$ ) program in Australia as a demonstration project to address changes in health care policy and financing. The FCN program provides a comprehensive group of services (e.g., primary health care, health promotion/disease prevention, and care management) that is grounded in a religious and social framework provided by the faith community.

The collection of articles presented here is by no means exhaustive of the topics falling under the rubric of religion and health. As a group, however, they represent a sampling of the substantive questions and concerns that are current in this area and suggest the potential implications of these issues for research and practice in health education. The reemergence of interest in the significance of religion for the health of individuals and populations holds real promise for fostering rigorous theoretical and empirical efforts to understand these relationships, provides a sense of the significance of religion and faithbased settings for the lives of individuals and communities, and offers exciting opportunities for health education practice.

\section{References}

1. Levin JS, Vanderpool HY: Religious factors in physical health and the prevention of illness. Prev Human Ser 9:41-64, 1991.

2. Osler W: The faith that heals. British Med J, June 18, 1910, pp. 1470-1472.

3. Paulsen AE: Religious healing: A preliminary report. JAMA 86:1519-1522, 1617-1623, 1692-1697, 1926.

4. Moberg DO: The Christian religion and personal adjustment in old age. Am Soc Rev 18:87-90, 1953.

5. Srole L, Langner T: Religious origin, in Srole L, Langner RS, Michael ST, Opler MK, Rennie TAC (eds.): Mental Health in the Metropolis: The Midtown Manhattan Study. New York, McGraw-Hill, 1962, pp. 300-324. 
6. Ibrahim MA, Kaplan BH, Patrick RC, Slome C, Tyroler H, Wilson RN: The legacy of John Cassel. Am J Epid 112:1-7, 1980.

7. Graham TW, Kaplan BH, Cornoni-Huntley JC, James SA, Becker C, Hames CG, Heyden S: Frequency of church attendance and blood pressure elevation. J Behav Med 1:37-43, 1978.

8. Ellison CG: Religion, the life stress paradigm, and the study of depression, in Levin JS (ed.): Religion in Aging and Health: Theoretical Foundations and Methodological Frontiers. Thousand Oaks, CA, Sage, 1994, pp. 78-121.

9. Koenig HG: Aging and God: Spiritual Pathways to Mental Health in Midlife and Later Years. New York, Haworth, 1992.

10. Levin JS: Religion and health: Is there an association, is it valid, and is it causal? Soc Sci Med 38:1475-1482, 1994.

11. Levin JS, Schiller PL: Is there a religious factor in health? J Religion Health 26:9-35, 1987.

12. Levin JS, Vanderpool HY: Is frequent religious attendance really conducive to better health? Toward an epidemiology of religion. Soc Sci Med 24:589-600, 1987.

13. Bergin AE: Religiosity and mental health: A critical re-evaluation and meta-analysis. Professional Psychol: Res Prac 14:170-184, 1983.

14. Larson DB, Pattison EM, Blazer DG, Omran AR, Kaplan BH: Systematic analysis of research on religious variables in four major psychiatric journals, 1978-1982. Am J Psychiatry 143:329-334, 1986.

15. Gartner JD, Larson DB, Allen GD: Religious commitment and mental health: A review of the empirical literature. J Psychol Theol 19:6-25, 1991.

16. Larson DB, Sherrill KA, Lyons JS, Craigie FC, Thielman SB, Greenwold MA, Larson SS: Associations between dimensions of religious commitment and mental health reported in the American Journal of Psychiatry and Archives of General Psychiatry: 1978-1989. Am J Psychiatry 149:557-559, 1992.

17. Jarvis GK, Northcott HC: Religion and differences in morbidity and mortality. Soc Sci Med 25:813-824, 1987.

18. Troyer H: Review of cancer among 4 religious sects: Evidence that life-styles are distinctive sets of risk factors. Soc Sci Med 26:1007-1017, 1988.

19. Witter RA, Stock WA, Okun MA, Haring MJ: Religion and subjective well-being in adulthood: A quantitative synthesis. Rev Religious Res 26:332-342, 1985.

20. Levin JS: Religion factors in aging, adjustment, and health: A theoretical overview. J Religion and Aging 4(3-4):133-146, 1988.

21. Moberg DO: Religion and aging, in Ferraro KR (ed.): Gerontology: Perspectives and Issues. New York, Springer, 1990, pp. 179-205.

22. Levin JS, Tobin SS: Religion and psychological well-being, in Kimble MA, McFadden SH, Ellor JW, Seeber JJ (eds.): Handbook of Religion, Spirituality, and Aging. Minneapolis, Fortress, 1995, pp. 30-46.

23. Levin JS, Vanderpool HY: Religious factors in physical health and the prevention of illness, in Pargament KI, Maton KI, Hess RE (eds.): Religion and Prevention in Mental Health: Research, Vision and Action. New York, Haworth, 1992, pp. 83-103.

24. Schiller PL, Levin JS: Is there a religious factor in health care utilization? A review. Soc Sci Med 27:1369-1379, 1988.

25. Levin JS, Chatters LM, Ellison CG, Taylor RJ: Religious involvement, health outcomes, and public health practice. Current Issues Public Health 2:220-225, 1996.

26. Chatters LM, Levin JS, Taylor RJ: Antecedents and dimensions of religious involvement among older Black adults. J Gerontol: Soc Sci 47:S269-S278, 1992.

27. Levin JS, Chatters LM, Taylor RJ: Religious effects on health and life satisfaction among Black Americans. J Gerontol: Soc Sci 50B:S154-S163, 1995.

28. Williams DR: The measurement of religion in epidemiologic studies: Problems and prospects, in Levin JS (ed.): Religion in Aging and Health: Theoretical Foundations and Methodological Frontiers. Thousand Oaks, CA, Sage, 1994. 
29. Westberg GF: Churches are joining the health care team. Urban Health 13(9):34-36, 1973.

30. Hatch JW, Jackson C: North Carolina Baptist church program. Urban Health, May, 1981, pp. 70-71.

31. Hatch JW, Callan AE, Eng E, Jackson C: The General Baptist State Convention Health and Human Services Project. Contact 77:1-7, 1984.

32. Quinn PK, Talley K: A clergy training program in a mental health center. Hosp Community Psychiatry 25:472-473, 1974.

33. Haugk KC: Unique contributions of churches and clergy to community mental health. Community Mental Health J 12:20-28, 1976.

34. Bentz WK: The clergyman's role in community mental health. J Religion Health 9:7-15, 1970.

35. Levin JS: The role of the Black church in community medicine. J Natl Med Assoc 76:477-483, 1984.

36. Levin JS: Roles for the Black pastor in prevention medicine. Pastoral Psychol 35:94-102, 1986.

37. Evans CA Jr: Links to faith community may help public health. The Nation's Health, January, 1995, p. 2.

38. Peterson B: Renewing the church's health ministries: Reflections on ten years' experience. J Religion Appl Behav Sci 4(3):16-22, 1983.

39. Olson LM, Reis J, Murphy L, Gehm JH: The religious community as a partner in health care. J Community Health 13:249-257, 1988.

40. Miller JT: Wellness programs through the church: Available alternative for health education. Health Values 11:3-6, 1987.

41. McKee DD, Chappel JN: Spirituality and medical practice. J Fam Practice 35:201, 205-208, 1992.

42. Hadden J: Desacralizing secularization theory. Social Forces 65:587-611, 1987.

43. Davis JA, Smith TW: General Social Surveys: Cumulative Codebook, 1972-1996. Chicago, National Opinion Research Center, 1996.

44. A symposium on church attendance in the United States. Am Sociological Rev 63(1):111-145, 1998.

45. Sherkat DE, Ellison CG, Simpson JH: Recent developments and current controversies in the sociology of religion. Ann Rev Sociology, in press.

46. Eng E, Hatch J, Callan A: Institutionalizing social support through the church and into the community. Health Educ Q 12:81-92, 1985.

47. Kumanyika SK, Charleston JB: Lose weight and win: A church-based weight loss program for blood pressure control among Black women. Pat Educ Couns 19:19-32, 1992.

48. Thomas SB, Quinn SC, Billingsley A, Caldwell C: The characteristics of Northern Black churches with community health outreach programs. Am J Pub Health 84:575-579, 1994.

49. Association for the Advancement of Health Education: Code of ethics for health educators. J Health Educ 25(4): 197-200, 1994.

50. Forster JL: A communitarian ethical model for public health interventions: An alternative to individual behavior change strategies. J Pub Health Pol 3:150-163, 1982.

51. Bruder EE: The clergyman's role in community mental health. J Religion Health 9:7-15, 1970.

52. Levell HR, Clark EG: Preventive Medicine for the Doctor in His Community (3rd ed.). New York, McGraw-Hill, 1965.

53. Perry EJ, Williams BJ: Memphis TN: The Memphis church-based high blood pressure program. Urban Health 10:69-70, 1981.

54. Billingsley A, Caldwell CH, Rouse WV: Black Churches and Family-Oriented Community Outreach Programs in the Northeastern United States. Final report submitted to the Ford Foundation and Lilly Endowment, June, 1991.

55. Levin JS, Taylor RJ, Chatters LM: A multidimensional measure of religious involvement for African Americans. Sociological Q 36:157-173, 1995.

56. Krause N, Tran TV: Stress and religious involvement among older Blacks. J Gerontol: Soc Sci 44:S4-S13, 1989. 
57. Levin JS: How religion influences morbidity and health: Reflections on natural history, salutogenesis and host resistance. Soc Sci Med 43:849-864, 1996. 